\title{
List of words to evaluate speech perception: recording and verification of applicability
}

\author{
Grace Kelly de Souza Seixas Ciscare ${ }^{1}$ \\ https://orcid.org/0000-0002-7005-4835 \\ Julia Speranza Zabeu ${ }^{2}$ \\ https://orcid.org/0000-0003-4254-9299 \\ Djane Rosa dos Santos ${ }^{1}$ \\ https://orcid.org/0000-0002-2797-5188 \\ Marina Morettin-Zupelari ${ }^{3}$ \\ https://orcid.org/0000-0003-2577-374X \\ Eliane Maria Carrit Delgado-Pinheiro 4 \\ https://orcid.org/0000-0002-7589-2125 \\ Natália Barreto Frederigue-Lopes ${ }^{3}$ \\ https://orcid.org/0000-0001-6738-3278
}
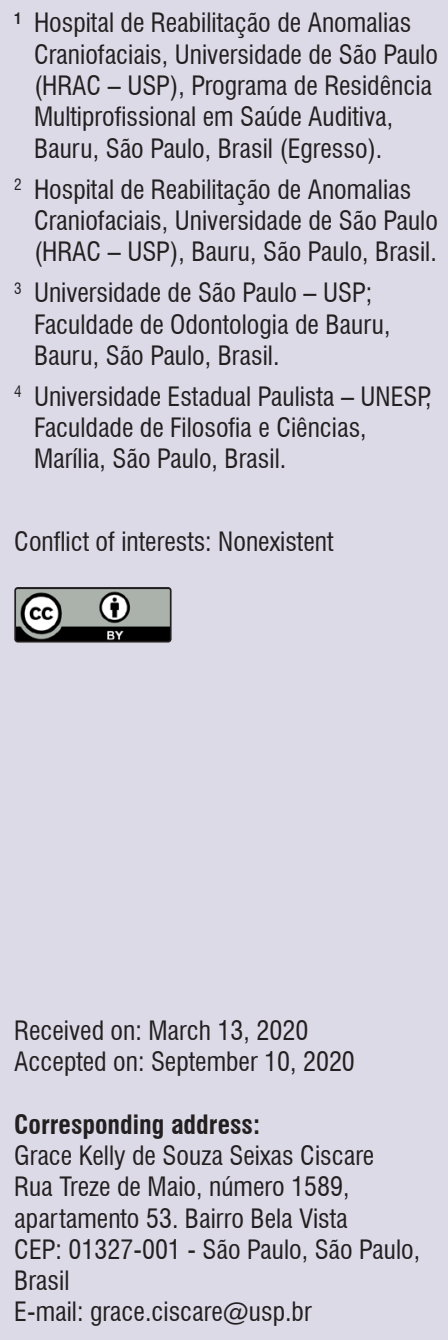

\section{ABSTRACT}

Purpose: to record the "List of Words to Evaluate the Speech Perception of Children with Hearing Loss" which is standardized for live speech presentation and verify its clinical applicability.

Methods: recording: acoustic standards were used, three recordings of each word and analysis by judges. The list was recorded in silence at 60 decibels $(\mathrm{dB})$ and signal noise relation of $+10 \mathrm{~dB}$. Participants: 30 children in the age range from five years to 10 years and 11 months, with no auditory and language disorders. The procedure was performed in live and recorded speech. Wilcoxon's, paired $t$ and Spearman's correlation coefficient tests ( $p$-value significantly less or equal to 0.05 ), were applied.

Results: the comparison of performance for recognition of words and phonemes between live and recorded speech resulted in a statistically significant difference $(p \leq 0.05)$, in all conditions analyzed. The results were higher in the silence condition. There was no statistically significant difference between the time of application in the recorded speech when compared in silence and noise $(p=0.064)$.

Conclusion: the recording and application of the procedure that analyzes recognition of phonemes and words proved to be viable in recorded speech in silence and noise.

Keywords: Hearing Loss; Child; Speech Perception; Hearing Aids; Cochlear Implant 


\section{INTRODUCTION}

Complete access to environmental and speech sounds is of fundamental importance to the acquisition and development of language and communicative skills, learning and social interaction. In this regard, hearing loss can significantly compromise the biopsychosocial development of a child. Thus, early diagnosis and rehabilitation are important ${ }^{1}$.

In order for the child with hearing loss to develop satisfactorily, the evaluation and monitoring of hearing and speech results, with the hearing aid (HA) and cochlear implant $(\mathrm{Cl})$, provide the identification of specific needs of the child, guiding the therapeutic planning, assisting in the identification of factors that may interfere in the child's development, establishing realistic expectations, and contributing to family orientation and counseling.

The recognition of speech sounds is an important aspect to be measured in auditory function, considering that it allows the evaluation of the receptive communicative function. Since it is a challenging task, its evaluation provides important information about the individual's ability to deal with hearing, especially in noisy environments ${ }^{2}$.

The use of standardized procedures that assess the perception of speech sounds in the infant population allows the validation of the intervention and the reliability of the results obtained. These procedures make it possible to measure the amount of speech sounds the child with hearing impairment is able to extract from the acoustic information that reaches their dynamic field of hearing, considering that having greater retention of acoustic information increases the chances of developing oral language ${ }^{3}$.

In the literature there are validated evaluation protocols for the Portuguese language in order to evaluate the level of speech perception of the individual. These evaluations contribute significantly to the verification of the auditory development of children with hearing impairment, however, with technological advances and the possibility of early access to speech sounds, there is a need for higher specifications by age group, form of stimulus presentation (live or recorded voice), intensity of stimulus presentation and degree of difficulty.

Delgado and Bevilacqua (1999) developed a tool referred to as the "List of Words to Evaluate the Speech Perception of Children with Hearing Loss," with the purpose of providing a procedure to evaluate speech perception. This tool was designed for children between five and ten years of age. The speech stimulus consists of a list of 20 disyllabic words, phonetically balanced, with a consonant-vowel-consonant-vowel structure (CVCV), presented in live speech mode, in an acoustically isolated booth with an audiometer. Performance is evaluated by the score in the recognition of phonemes and words. The evidence of auditory ability is advanced hearing recognition or identification ${ }^{4}$.

The clinical applicability of the "List of Words to Evaluate the Speech Perception of Children with Hearing Loss" has been highlighted by several studies. This procedure was used in studies with the aim of evaluating auditory performance in children with cochlear implants $(\mathrm{Cl})$, which allowed to demonstrate the beneficial results of $\mathrm{Cl}$ in relation to the development of auditory abilities ${ }^{5,6}$. Other studies applied this procedure to evaluate advanced auditory recognition, demonstrating the correlation with the aspects related to voice and speech production of children and teenagers with hearing loss ${ }^{7}$.

When the test is applied in live speech mode some vocal characteristics of the examiner, such as: sex, pronunciation, fluency, and regional accent directly influence test conditions. Intonation, accent or any alteration in vocal quality may interfere in the results of the evaluation. The vocal characteristics of the examiner may vary the way in which the information is perceived and processed by the listener, since the vocal spectrum of the examiner reflects directly in the quality of the material presented ${ }^{8}$.

Brazil has a vast territorial extension and one of the largest and most complex public health systems in in the world. The Cochlear Implant Centers authorized by the Unified Health System are distributed among several regions in the country, currently totaling 37 institutions ${ }^{9}$. Due to territorial distance, the attention to procedure regulations and the establishment of standardizations are the difficulties being faced.

In accordance, the importance of homogeneity in procedures is noted, especially the speech perception tests, because eventual methodological differences that occur, either in the follow-up of the patient with $\mathrm{Cl}$ or even in the tests used for their evaluation, imply possible difficulties in evaluating the performance and benefits that $\mathrm{Cl}$ surgery can provide the patient ${ }^{10}$.

The breakdown of the recording process and results may help the licensed services in different regions to perform the recording procedures, thus considering the characteristics of regional accent. 
The standardization of the tools used in speech perception tests is a fundamental condition to ensure their reliability; therefore, the use of recorded speech ensures that the same procedures and stimuli are applied and that the test and retest data can be compared between different examiners and different institutions, thus reducing extrinsic redundancies and the influence of the evaluator on the final result ${ }^{11,12}$.

In view of the above, this study aimed to record the "List of Words to Evaluate Speech Perception of Children with Hearing Loss", which is standardized for the application of live speech, and to verify the applicability of the recording.

\section{METHODS}

This is a clinical, cross-sectional study conducted with the approval of the Ethical and Research Committee of the Hospital de Reabilitação de Anomalias Craniofaciais da Universidade de São Paulo, SP, Brazil, CAAE 64680017.7.0000.5441, under process number 2.060.349, and developed in specific stages described below.

\section{Recording the "List of Words to Evaluate the Speech Perception of Children with Hearing Loss" in silent and noisy conditions}

The test was recorded in an acoustically treated studio by a speaker with clear and precise articulation so that the ideal pronunciation of the stimuli was respected, without distortion of the sounds. The recording was prepared and digitized by a professional audio editing software - Sound Forge 10.0. Each word on the list was recorded three times. The selection of the words for the recorded list was decided by the auditory-perceptual judgment of three audiologists independently using the Windows Media Player Program (Microsoft). The audiologists were instructed to judge each word aurally and, subsequently mark one of the alternatives for each speech sample evaluated in a pre-elaborated spreadsheet for this purpose. The inter-stimulus time interval was 4 seconds, because this is an interval that presupposes the time required for the child's response in the test situation. The list was recorded under two conditions: silence (fixed intensity - 60 decibels Sound Pressure Level - dB SPL) and noise (composed of classroom noises found in regular schools) in order to make it possible to evaluate speech perception with consistent noise. This was obtained from the study of Santos $(2015)^{13}$, and from the manipulation of the the noise material developed by Fidêncio $(2013)^{14}$. The noise was recorded at a fixed intensity enabling the signal/noise ratio of $+10 \mathrm{~dB}$ (speech stimulus at $60 \mathrm{~dB}$ SPL and the noise stimulus at $50 \mathrm{~dB}$ SPL), according to the protocol of the institution involved.

\section{Participants}

The participants were selected according to the following criteria: ages between five years and ten years and eleven months; normal hearing; absence of cerumen impaction or other associated alterations of the external and middle ear; absence of academic and language complainments. Normal hearing was confirmed by inspection of the external auditory canal, otoscopy with Heine otoscope; tympanometry with Titan-Interacoustics Tympanometer with type A curve responses; hearing screening, by verifying the airway thresholds for $500 \mathrm{~Hz}, 1000 \mathrm{~Hz}, 2000 \mathrm{~Hz}$, and $4000 \mathrm{~Hz}$ considering responses with values below 15 $\mathrm{dB}$ for each frequency evaluated for both ears ${ }^{15,16}$ with Pediatric Audiometer (PA5) - Interacoustics, TDH 39 headphone. The typical language development was confirmed through the application of the phonology tests of the Child Language Test - ABFW in the areas of phonology, vocabulary, fluency, and pragmatics ${ }^{17}$. The normality values adopted were those recommended in the literature for each instrument and test. In accordance with the standards, the sample consisted of 30 children, 20 females and 10 males, from ages five years to ten years and 11 months. The sample was divided into six groups, and the chosen age group was the same as the one recommended for the original test; G1: five years to five years and eleven months; G2: six years to six years and eleven months; G3: seven years to seven years and eleven months; G4: eight years to eight years and eleven months; G5: nine years to nine years and eleven months; G6: ten years to ten years and eleven months. All parents or guardians and children agreed to participate in this study and signed an informed consent form.

\section{The application of the speech perception test in children with typical development of hearing and language}

A pure tone $(1000 \mathrm{~Hz})$ was employed to establish the calibration parameters of the audiometer (AsteraMadsen) for the presentation of speech (words) and sound stimulus. Calibration was performed because 
speech stimulus is complex, having variability between the most and the least intense sounds ${ }^{18}$. With this procedure, it is possible to guarantee that the presentation of the speech stimulus is constant. The output of each channel was calibrated using the audio volume meter (V.U.) of the audiometer set at zero.

The "List of Words to Evaluate the Speech Perception of Children with Hearing Loss" in the selected sample was used in a free field, using an acoustic booth of $2 \mathrm{~m}$ $x 2 \mathrm{~m}$. The children were positioned at a distance of 1 meter from the speaker at $0^{\circ}$ azimuth, and they were not familiar with the words before starting the test. The children had to repeat each word that was being said by the professional who was outside the booth with a microphone connected to the Headset, who then recorded the answers of each child evaluated. The conditions of the evaluation were as follows: test of the list recorded in silence and with noise; test of the list with live voice in silence and with noise. The noise was presented in the same speaker as the speech stimulus, positioned at $0^{\circ}$ azimuth. The presentation of the words in the list was random and the time for each situation was timed and scored in seconds.

\section{Results analysis}

The Kolmogorov-Smirnov test was used to verify the distribution of data from different situations and conditions. The speech perception test results did not follow a normal distribution, thus, the Wilcoxon's test was selected to compare the responses regarding the recognition of phonemes and words in silent and noise conditions, followed by the performance in the condition of silence and noise in the recorded speech situation. The median, the first and third quartiles were calculated and a p-value of less than or equal to 0.05 was considered statistically significant.

The total time (in seconds) of the application of the test followed a normal distribution, and the paired $t$-test was selected to verify if there was a difference in the results between the live voice and the recorded voice in the two different conditions.

The Spearman's correlation coefficient was adopted to investigate the correlation between the variables: age, performance in different conditions and situations and the total time of the application of the test.

The classification of correlation coefficient adopted for interpretation of the correlation magnitude was: correlation coefficient $<0.4$ (correlation of weak magnitude), $r \geq 0.4$ and $r<0.5$ (moderate magnitude), and $r \geq 0.5$ (strong magnitude) ${ }^{19}$.

\section{RESULTS}

The medians in both situations (live and recorded voice) were equal or nearly equal for the conditions of silence and noise, because most of the 30 children in the sample reached $100 \%$ of the phonemes and word recognition (Figure 1).

\begin{tabular}{|l|c|c|}
\hline Situation & Number of children with $\mathbf{1 0 0} \%$ & Number of children below $\mathbf{1 0 0} \%$ \\
\hline Phoneme Live Speech & 22 & 8 \\
\hline Silence & 22 & 8 \\
\hline Phoneme Recorded, Silence & 29 & 23 \\
\hline Phoneme Live Speech, Noise & 7 & 9 \\
\hline Phoneme Recorded, Noise & 21 & 8 \\
\hline Word Recognition Live Speech, Silence & 22 & 1 \\
\hline Word Recognition Recorded, Silence & 29 & 23 \\
\hline Word Recognition Live Speech, Noise & 7 & 9 \\
\hline Word Recognition Recorded, Noise & 21 & \\
\hline
\end{tabular}

Figure 1. Number of children with maximum performance obtained in the different conditions and situations of the evaluation ( $N=30)$ 
All children $(n=30)$ completed the tasks in both conditions (silence and noise) and both situations (live and recorded voice). The comparison of performance in recognition ability for phonemes and words between the live voice and the recorded voice situations resulted in statistically significant differences $(p \leq 0,05)$ in all situations (Table 1).

Table 1. Comparison of performance in live speech and recorded situations for the different conditions of the evaluation $(\mathrm{N}=30)$

\begin{tabular}{|c|c|c|c|c|c|c|}
\hline Situation & Median & $25^{\text {th }}$ Percentile & $75^{\text {th }}$ Percentile & Mean & $\begin{array}{l}\text { Standard } \\
\text { Deviation }\end{array}$ & $p$-value \\
\hline PRLSS & $100.0 \%$ & $97.5 \%$ & $100.0 \%$ & $98.7 \%$ & $2.5 \%$ & \multirow{2}{*}{$0.012 *$} \\
\hline PRRS & $100.0 \%$ & $100.0 \%$ & $100.0 \%$ & $99.9 \%$ & $0.5 \%$ & \\
\hline WRLSS & $100.0 \%$ & $95.0 \%$ & $100.0 \%$ & $98.5 \%$ & $2.7 \%$ & \multirow{2}{*}{$0.027^{*}$} \\
\hline WRRS & $100.0 \%$ & $100.0 \%$ & $100.0 \%$ & $99.8 \%$ & $0.9 \%$ & \\
\hline PRLSN & $95.0 \%$ & $92.5 \%$ & $99.1 \%$ & $94.8 \%$ & $4.5 \%$ & \multirow{2}{*}{$<0.001^{*}$} \\
\hline PRRN & $100.0 \%$ & $98.8 \%$ & $100.0 \%$ & $98.9 \%$ & $2.4 \%$ & \\
\hline WRLSN & $95.0 \%$ & $90.0 \%$ & $96.3 \%$ & $92.7 \%$ & $5.7 \%$ & \multirow{2}{*}{$<0.001^{*}$} \\
\hline WRRN & $100.0 \%$ & $95.0 \%$ & $100.0 \%$ & $98.2 \%$ & $3.3 \%$ & \\
\hline
\end{tabular}

PRLSS: Phoneme recognition in live speech and silence; PRRS: Phoneme recognition recording in silence; WRLSS: Word recognition in live speech and silence; WRRS: Word recognition in recording and silence; PRLSN: Phoneme recognition in live speech and noise; PRRN-Phoneme recognition in recording and noise; WRLSN-Word recognition in live speech and noise; WRRN-Word recognition in recording and noise. Statistical test used: Wilcoxon.

* Significant at $p \leq 0.05$.

Table 2 shows that the differences between the answers obtained in the conditions of silence and noise in both situations were significantly different in all four cases.

Table 2. Comparison of performance in silence and noise conditions and recording situation ( $N=30)$

\begin{tabular}{lcccccc}
\hline Situation & Median & 25 $^{\text {th }}$ Percentile & $\mathbf{7 5}^{\text {th }}$ Percentile & Mean & $\begin{array}{c}\text { Standard } \\
\text { Deviation }\end{array}$ & $\boldsymbol{p}_{\text {-value }}$ \\
\hline PRRS & $100.0 \%$ & $100.0 \%$ & $100.0 \%$ & $99.9 \%$ & $0.5 \%$ & $0.008^{*}$ \\
PRRN & $100.0 \%$ & $98.8 \%$ & $100.0 \%$ & $98.9 \%$ & $2.4 \%$ & \\
WRRS & $100.0 \%$ & $100.0 \%$ & $100.0 \%$ & $99.8 \%$ & $0.9 \%$ & $0.008^{*}$ \\
WRRN & $100.0 \%$ & $95.0 \%$ & $100.0 \%$ & $98.2 \%$ & $3.3 \%$ & ${ }^{*}$
\end{tabular}

PRLSS: Phoneme recognition in live speech and silence; PRRS: Phoneme recognition recording in silence; WRLSS: Word recognition in live speech and silence; WRRS: Word recognition in recording and silence; PRLSN: Phoneme recognition in live speech and noise; PRRN-Phoneme recognition in recording and noise; WRLSN-Word recognition in live speech and noise; WRRN-Word recognition in recording and noise. Statistical test used: Wilcoxon.

*Significant at $p \leq 0.05$.

It was observed that the time of the application of the test was shorter for the live voice situation compared to that of the recorded voice, in both conditions (silence and noise), and the difference was found statistically significant (Table 3). No statistically significant difference was found in the comparison of time of application for the recorded voice situation for either condition - silence or noise (Table 4). 
Table 3. Mean, minimum, maximum and standard deviation of time (in seconds) of evaluation and P-value (paired $t$-test) in the different conditions (live speech and recorded) $(\mathrm{N}=30)$

\begin{tabular}{|c|c|c|c|c|c|}
\hline Situation & Mean & Minimum & Maximum & Standard Deviation & $p$-value \\
\hline Time silence LS & 46.08 & 35.00 & 58.00 & 4.34 & \multirow{2}{*}{$0.000^{*}$} \\
\hline Time silence Recorded & 93.77 & 87.00 & 100.00 & 3.65 & \\
\hline Time noise LS & 62.62 & 49.00 & 90.00 & 9.06 & \multirow{2}{*}{$0.000 *$} \\
\hline Time noise Recorded & 95.54 & 85.00 & 102.00 & 4.07 & \\
\hline
\end{tabular}

LS-Live Speech. Statistical test used: $t$-test.

*Significant at $p \leq 0.05$.

Table 4. Comparison (paired t-test) between time of application (in seconds) between silence and noise situation in live speech and recording condition $(\mathrm{N}=30)$

\begin{tabular}{cc}
\hline Situation & $p$-value \\
\hline $\begin{array}{c}\text { Silence time LS } \\
\text { Noise time LS } \\
\text { Silence time recorded } \\
\text { Noise time recorded }\end{array}$ & $0.000^{*}$ \\
\hline
\end{tabular}

LS-Live Speech. Statistical test used: $t$-test

*Significant at $p \leq 0.05$

The Spearman's Correlation test was applied to determine whether performance under the different conditions and situations was correlated with the age of the child. A positive correlation of significant magnitude with the increase in the age of the child was observed (Table 5).

Table 5. Correlation between the age of the child and results obtained in the evaluation, under the different conditions and situations $(\mathrm{N}=30)$

\begin{tabular}{ccc}
\hline Situation & Spearman's Test & $\boldsymbol{p}$-value \\
\hline PRLSS & 0.37 & $0.046^{*}$ \\
PRRS & -0.05 & 0.773 \\
WRLSS & 0.38 & $0.040^{\star}$ \\
WRRS & -0.05 & 0.773 \\
PRLSN & -0.22 & 0.234 \\
PRRN & 0.49 & $0.006^{\star}$ \\
WRLSN & -0.12 & 0.540 \\
WRRN & 0.50 & $0.005^{\star}$ \\
\hline
\end{tabular}

PRLSS-Phoneme recognition live speech in silence; PRRS-Phoneme recognition recorded, in silence; WRLSS-Word recognition live speech in silence; WRRS-Word recognition recorded in silence; PRLSN-Phoneme recognition live speech in noise; PRRN-Phoneme recognition recorded in noise; WRLSN-Word recognition live speech in noise; WRRN-Word recognition recorded in noise. Statistical test used: Spearman correlation coefficient. The classification of correlation coefficient adopted for interpretation of the correlation magnitude was correlation coefficient $<0.4$ (correlation of weak magnitude), $r \geq 0.4$ and $r<0.5$ (moderate magnitude), and $r \geq 0.5$ (strong magnitude).

${ }^{*}$ Significant at $p \leq 0.05$. 


\section{DISCUSSION}

This research produced a recording of the speech perception test "List of Words to Evaluate the Speech Perception of Children with Hearing Loss" developed by Delgado and Bevilacqua (1999) ${ }^{4}$ and verified its clinical applicability. The results showed statistically significant differences between the live speech and the recorded speech situations, in both conditions evaluated: silence and noise. That is, the children evaluated presented better performance for phonemes and word recognition in the conditions of silence and noise in the recorded speech situation compared to live speech.

The results evidenced in Figure 1 show that the difference between the two situations was statistically significant. This was because in the recorded speech situation, most of the children had scores equal to $100 \%$, whereas, in the live speech situation, many of the children had scores of less than $100 \%$. Table 1 shows that the values, especially for the first quartile, for the recorded speech were higher than for live speech for the phonemes and words in both conditions of silence and noise.

It is important to emphasize that when the test is performed in the live speech situation, the performance results presented by the child may be influenced by inter- or intra-speaker variability, due to different characteristics, such as, accent, speaking rate, articulatory pattern, and intonation, among others. On the other hand, the recorded stimulus allows for the editing of the recording, so as to approach the recommended standards for the creation of this type of material, without experiencing the subtle interferences of speaker variability when speaking the same word at different moments ${ }^{20}$, allowing for test-retest reliability.

This is the case with other standardized tests in Portuguese, for example, the Hearing in Noise Test Brazil (HINT) $)^{21}$, the "Recognition of Daily Routine Phrases Test"22, "Phrases in Noise Test" (PINT-translated and validated in Portuguese ${ }^{23}$, and verbal tests related to the evaluation and rehabilitation of central auditory processing disorders, such as the "Staggered Spondaic Word" (SSW) ${ }^{24}$ and the "Dichotic Digit Test" $(\mathrm{DDT})^{25}$, which have presentation consistency.

The performance of phonemes and word recognition in the recorded speech situation was statistically higher in the silence condition (Table 2). In the application of the phoneme list in the silence condition, only one child obtained a performance score of less than $100 \%$, in comparison with nine children who obtained a performance score of less than $100 \%$ in the noise condition. For the word recognition list the same result was obtained. This result shows that the recording of the list was adequately performed and that the patterns used made the test more sensitive in detecting how the child is extracting the acoustic information from speech signals, in silence and noise.

According to the literature, to achieve satisfactory speech comprehension, some auditory tasks are necessary, such as attention, analysis, synthesis, and memory, among others. These skills, when associated, promote auditory recognition, which means extracting meaning from what is heard ${ }^{26}$. In this way, speech comprehension is one of the most complex activities that depends directly on peripheral hearing, central auditory processing and cognition ${ }^{27}$. In other words, in optimal hearing situations and acoustically comfortable environments, individuals with normal hearing are able to recognize speech easily. However, when the environment is degraded because of competitive noise or reverberation, it is common for individuals to experience difficulty in comprehension ${ }^{28}$.

Regarding the time of application of the lists, there was a significantly higher average in seconds for the recorded speech in both silence and noise condition ( $p$ - value $<0.001$ ). Due to its rapid applicability (a mean of 93.8 seconds in the silence condition and 95.5 seconds in the noise condition) this increased time required for the recorded speech probably does not imply losses to clinical practice when considering the demand for care, especially in the Auditory Health services of the Unified Health System. Moreover, no statistically significant relationship was found between the time of application of the recorded speech for either the silence or the noise condition. The application of the list did not produce fatigue among the children in this condition, and subsequently, both facts facilitate the use of this list.

A positive correlation of significant magnitude was found for performance in the noise condition and the recorded speech with the increase in the age of the children (Table 5). The better performance observed in the older children may have resulted from the development of compensatory strategies of paying attention to tasks ${ }^{29}$.

One study ${ }^{30}$ administered the hearing attention test to 280 children, aged 6-to-11-years. It showed that younger children made more mistakes than older children due to inattention and impulsivity and concluded that the scores were highly correlated with the age of the individuals, and that the ability to sustain 
attention deteriorates with the time of the task for the entire sampled group.

It is worth mentioning that few options exist for recorded speech perception tests in Portuguese or adapted into Portuguese, especially for the child population, emphasizing the importance of research in this field.

It is essential that efforts be undertaken to ensure that the protocols for continuous evaluation and the follow-up of children with hearing loss included in the aurioral approach follow technological innovations and clinical and scientific evidence based on existing results. In this context, it is necessary to identify current needs and propose innovations and updates.

\section{CONCLUSION}

The recording of the "List of Words for the Evaluation of Speech Perception for Children with Hearing Loss" proved to be a viable application for the population being studied. This procedure may contribute to the improvement of protocols for evaluating auditory skills in children presented with hearing loss who use hearing aids and/or cochlear implants.

\section{ACKNOWLEDGEMENT}

We appreciate speech therapist Ms. Milena Maria Ramalho Matta Vieira for her contribution in the recording of the "List of Words to Evaluate the Speech Perception of Children with Hearing Loss".

\section{REFERENCES}

1. Rabelo GRG, Melo LPF. Counselling in the rehabilitating process for hearing impaired children by parents' perspective. Rev. CEFAC. 2016;18(2):362-8.

2. Becker KT, Costa MJ, Lessa AH. Speech recognition in students from seven to tem years old from two different socioeconomic-cultural levels. Rev. CEFAC. 2013;15(5):1148-55.

3. Padinha RB, Deperon TM, Mendes BCA, Novaes BCAC. Speech perception: performance parameters and implications for speech therapy with hearing impaired children. Distúrb. Comum. 2016;28(1):38-49.

4. Delgado EMC, Bevilacqua MC. Lista de palavras como procedimento de avaliação da percepção dos sons da fala para crianças deficientes auditivas. Pró-Fono R. Atual. Cientif. 1999;11(1):59-64.
5. Angelo TCS, Bevilacqua MC, Moret ALM. Percepção da fala em deficientes auditivos pré-linguais usuários de implante coclear. Pró-Fono R. Atual. Científ. 2010;22(3):275-80.

6. Carvalho ACM, Bevilacqua MC, Sameshima K, Costa Filho OA. Auditory neuropathy / auditory dyssynchrony in children with cochlear implants. Braz J Otorhinolaryngol. 2011;77 (4):481-7.

7. Santos FR. Investigação das relações entre voz, produção da fala de crianças e adolescentes deficientes auditivos [Dissertação]. São Paulo (SP): Faculdade de Filosofia e Ciências, da Universidade Estadual Paulista - Campus de Marília; 2020.

8. Portmann M, Portmann C. In: Tratado de audiometria clínica. 6⿳亠 ed. São Paulo: Rocca, 1993. p. 59-78.

9. Departamento de Informática do Sistema Único de Saúde. [acesso em 02 jun 2020]. Disponível em: https:||www.datasus.saude.gov.br/

10. Mafra NV. Comparação do desempenho de indivíduos normoouvintes no teste de índice de reconhecimento de fala a viva voz regional e fala gravada paranaense em diferentes cidades do Brasil [Dissertação]. Curitiba (PR): Universidade Tuiuti do Paraná; 2015.

11. Lima NM, Momensohn-Santos TM. Performance of adults with hearing loss on speech recognition index with recorded and live voice material. Distúrb. Comum. 2016;28(3):523-9.

12. Andrade AN, lorio MCM, Gila D. Speech recognition in individuals with sensorineural hearing loss. Braz J Otorhinolaryngol. 2016;82(3):334-40.

13. Santos LG. Phrases in Noise Test (PINT): adaptação cultural para o Português Brasileiro e aplicabilidade na avaliação do Sistema Frequência Modulada [Dissertação]. São Paulo (SP): Faculdade de Odontologia de Bauru da Universidade de São Paulo; 2015.

14. Fidêncio VLD. Avaliação digital do efeito do ruído sobre a fala: relação sinal/ruído [Dissertação]. São Paulo (SP): Faculdade de Odontologia de Bauru da Universidade de São Paulo; 2013.

15. Northen JL, Downs MP. Hearing in children. $5^{\mathrm{a}}$ ed. Lippincott, Williams e Wilkins, Philadelphia, 2002.

16. Organização Mundial da Saúde - OMS, 2014 http:// www.who.int/pbd/deafness/hearing_impairment_ grades/en/ acesso em 09.06.2020. 
17. Wertzner HF. Fonologia (Parte A). In: Andrade CRF, Befi-Lopes DM, Fernandes FDM, Wertzner HF (orgs). ABFW - Teste de Linguagem Infantil nas Áreas de Fonologia, Vocabulário, Fluência e Pragmática. $2^{\mathrm{a} e d .}$ Barueri: Pró-Fono. 2004. p.51-81.

18. Boothroyd A. Speech perception, sensorineural hearing loss and hearing aid. In: Studevaker G, Hochberg I (orgs). Acoustical factors affecting hearing aid performance. $2^{a}$ ed. Boston: Allyn \& Bacon; 1993. p.277-99.

19. Hulley SB, Cummings SR, Browner WS, Grady D, Hearst N, Newman TB. Delineando a pesquisa clínica: uma abordagem epidemiológica. 2a ed. Porto Alegre: Editora Artmed; 2003.

20. Seiva AS, Momensohn-Santos TM, Fortes CC, Queiroz DS. Performance of individuals in the test of speech recognition index to live voice and recorded speech presentation. Distúrb. Comum. 2012;24(3):351-8.

21. Sbompato AF, Corteletti LCBJ, Moret ALM, Jacob RTS. Hearing in Noise Test Brazil: standardization for young adults with normal hearing. Braz $J$ Otorhinolaryngol. 2015;8(4):384-8.

22. Oliveira ST. Avaliação da percepção da fala utilizando sentenças do dia-a-dia [Dissertação]. São Paulo (SP): Pontíficia Universidade Católica de São Paulo; 1992.

23. Silva CS da, Rosa BC, Alvarenga BG, Jacob RTS. Phrases in noise test (PINT) Brasil: efetividade do teste em crianças com perda auditiva moderada e severa [Dissertação]. São Paulo (SP): Faculdade de Odontologia de Bauru da Universidade de São Paulo; 2017.

24. Borges ACLC. Adaptação do teste SSW para a língua portuguesa: nota preliminar. Acta Awho. 1986;5(suppl. 1):38-40.

25. Santos FMC, Pereira LD. Escuta com dígitos. In: Pereira LD, Schochat E (orgs). Processamento auditivo central: manual de avaliação. São Paulo: Lovise; 1997. p.147-50.

26. Almeida GV, Ribas A, Calleros J. Free Field Word recognition test in the presence of noise in normal hearing adults. Braz $\mathrm{J}$ Otorhinolaryngol. 2017;83(3):665-9.

27. Anderson S, White-Schwoch T, Parbery-Clark A, Kraus N. A dynamic auditory-cognitive system supports speech-in-noise perception in older adults. Hear Res. 2013;300:18-32.
28. Santos JF, Seligman L, Tochetto TM. Acoustical comfort in the perception of literate school children. Rev Soc Bras Fonoaudiol. 2012;17(3):254-9.

29. Keith RW. ACPT: Auditory Continuous Performance Test. San Antonio, TX, Psychological Corporation, 1994.

30. Feniman MR. Aplicação do teste de atenção auditiva FC2 em crianças ouvintes normais [Tese]. Bauru (SP): Faculdade de Odontologia de Bauru, Universidade de São Paulo; 2004. 